\title{
All that wheezes is not asthma
}

\section{D A Goonasekera ${ }^{1}$, C K Abeysekera ${ }^{2}$, U A D D Munidasa ${ }^{3}$}

Sri Lanka Journal of Child Health, 2001; 30: 108-9

(Key words: wheeze not due to asthma)

.A two-year-old girl was referred urgently to our hospital with a less than 24-hour history of severe respiratory difficulty, wheezing and cyanosis. She had a tachycardia of 190/min and a respiratory rate of $70 / \mathrm{min}$. She was immediately transferred to the Intensive Care Unit and was intubated and ventilated. During ventilation her right-sided breath sounds were found to be diminished. A disproportionately high rate of ventilation $(22 / \mathrm{min})$ and $\mathrm{FiO} 2$ of $100 \%$ was required to establish adequate peripheral oxygen saturation (i.e. $>96 \%$ SpO2). Also, an unusually persistent baseline tachycardia of $160 / \mathrm{min}$ was observed, despite adequate sedation with pethidine and midazolam.

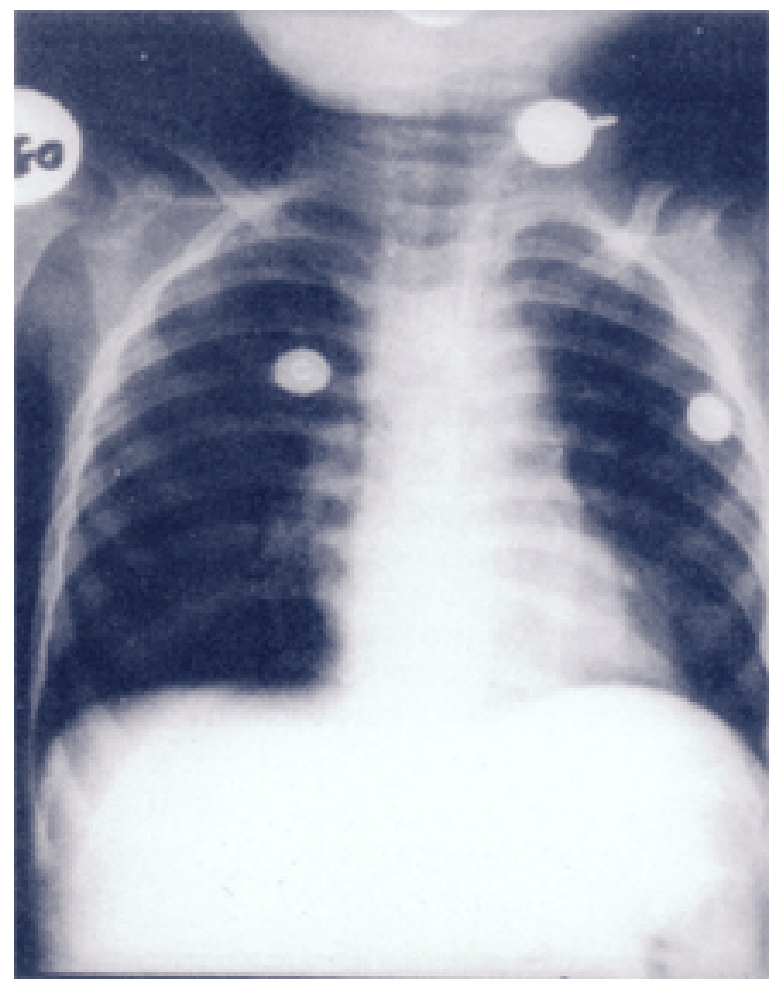

Figure 1 Chest $x$ ray showing totally collapsed right lung with ipsilateral mediastinal shift in the intubated child.

${ }^{1}$ Senior Lecturer, Dept. of Anaesthesiology, ${ }^{2}$ Senior Lecturer, Dept. of Paediatrics, ${ }^{3}$ Lecturer, Dept. of Anaesthesiology, Faculty of Medicine, Peradeniya

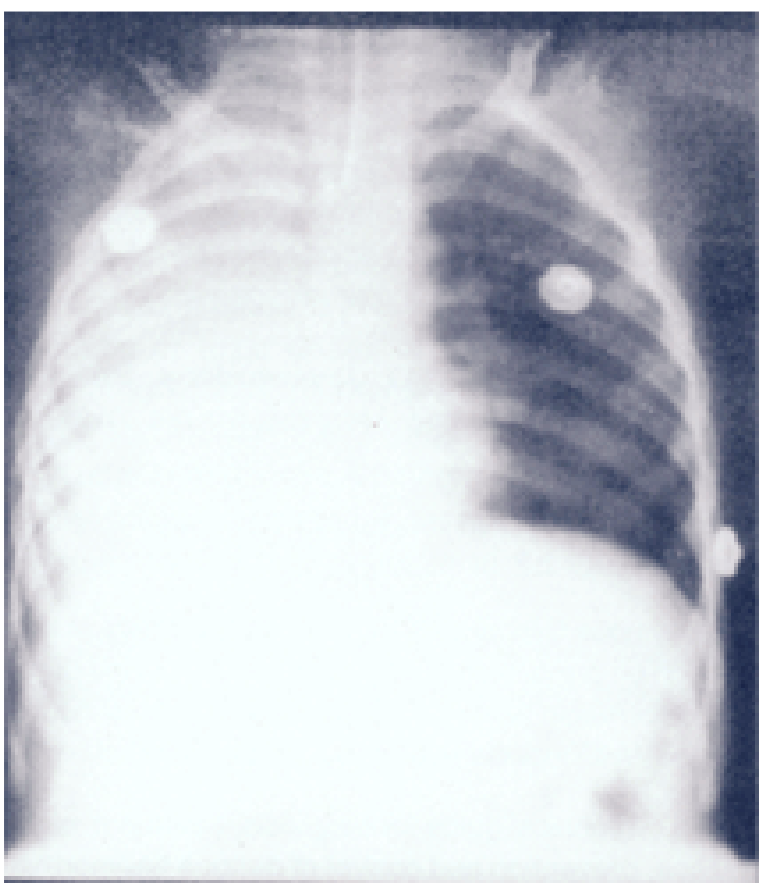

Figure 2 The chest $x$ ray on admission showing hyperinflated right lung where the right diaphragm is pushed down below that of the left

Subsequent history revealed no previous history of wheezing. There was neither choking nor family history of asthma. Sedation, paralysis and artificial ventilation were continued and 24 hours later the chest $\mathrm{x}$-rays showed a totally collapsed right lung (Figure 1) and this was attributed to aspiration. However, on careful re-evaluation, it became apparent that on admission, the previous day, the right lung had been over inflated compared to the left (Figure 2). This finding enabled us to suspect an inhaled foreign body. Even at this stage her disproportionate tachycardia of 170-180/min persisted.

Subsequently the child underwent bronchoscopy, at which, a swollen, germinating bean seed was found obstructing the right main bronchus. This was removed under general anaesthesia and she made a complete recovery. 
Asthma is not the only cause for wheezing. It is known that approximately $45 \%$ of children with airway foreign body aspiration present with wheezing as the predominant symptom ${ }^{1}$. An episode of choking is not reported in approximately half the children with aspirated airway foreign bodies requiring bronchoscopy. A substantial number is known to present with cough, reduced breath sounds and wheezing and the most frequently encountered radiological findings are air trapping and consolidation ${ }^{1}$. Surprisingly, inhaled foreign bodies are more often reported to lodge in the left bronchus despite its anatomical position ${ }^{2}$ and not in the right as in our case. However, in our case, when the patient simulated an attack of acute severe asthma at presentation, it was the negative past and family history, the high ventilatory requirements, the unusual tachycardia, and the picture of changing lung pathology that ultimately led us to the correct diagnosis. This case report highlights the unusual features we encountered, which should have made one suspect a cause other than bronchospasm for wheezing. The message is reiterated once again. Not all that wheezes is asthma ${ }^{3}$.

\section{References}

1. Oguz F, Citak A, Unuvar E, Sidal M. Airway foreign bodies in childhood. Int $J$ Pediatr Otorhinolaryngol 2000; 52: 11-6.

2. Yeh L C, Li H Y, Huang T S. Foreign bodies in tracheobronchial tree in children: a review of cases over a twenty year period. Changgeng $Y i$ Xue Za Zhi 1998; 21: 44-9.

3. Cupitt J M. Not all that wheezes is asthma. Anaesthesia 2001; 55: 1218. 
